\title{
Star researchers join Canadian Medical Hall of Fame
}

$\mathrm{T}$ he "father" of cardiovascular endocrinology and a trailblazer in disease gene discovery are among this year's inductees to the Canadian Medical Hall of Fame.

Six leaders in medicine and medical research were inducted into the hall in an Apr. 24 ceremony in Kingston, Ont. They joined the ranks of 101 Canadians who have received the national honour, which is awarded annually to recognize extraordinary contributions to the understanding of disease and advancement of health.

"We are looking for the innovators and individuals who are a little ahead of their time and whose actions in health care overall have been so paramount that they have changed the scene for Canadians, as well as people around the world," says executive director Lissa Foster.

This year's inductees include Dr. Adolfo de Bold, the scientist who isolated the cardiac hormone atrial natriuretic factor in 1981, demonstrating that the heart is not only a pump but an endocrine organ. The finding dramatically changed prevention and treatment of heart disease, and is credited as one of the most important cardiovascular discoveries in the past 50 years.

Another inductee and exemplary scientist, Dr. Ronald Worton, discovered the causal gene for Duchenne and Becker muscular dystrophy, revolutionizing diagnosis and patient care. Worton was also responsible for a substantial portion of Canada's contributions to the Human Genome Project.
The other 2014 inductees are:

- Dr. Max Cynader - a neuroscientist with a focus in multidisciplinary brain research. He is the founding director of the Djavad Mowfaghian Centre for Brain Health and the Brain Research Centre at the University of British Columbia in Vancouver.

in multiple sclerosis research. $\mathrm{He}$ founded and directed the Multiple Sclerosis Research Unit at Dalhousie University, in Halifax, Nova Scotia, and championed the integration of humanities into medical education.

- Dr. Salim Yusuf - a researcher best known for leading clinical trials involving tens of thousands of patients in dozens of countries, yielding important advances in the treatment and prevention of cardiovascular disease. $\mathrm{He}$ is the founder and director of the Population Health Research Institute at McMaster University in Hamilton, Ontario, and vicepresident of research at Hamilton Health Sciences.

Although the inductees represent a breadth of clinical and research expertise, Foster says the hall hopes to select future laureates from a greater diversity of disciplines.

"We are a bit research heavy," she says, explaining that "it's a natural thing," given the way that discoveries such as the isolation of a gene or identification of the heart as an endocrine organ can revolutionize medicine.

"We now have a dean of nursing on our selection com-

- Dr. Walter Mackenzie (posthumous) - the surgeon responsible for the development of numerous medical and surgical programs at the University of Alberta in Edmonton. He also played a pivotal role in the formation of the Alberta Heritage Foundation for Medical Research.

- Dr. Thomas "Jock" Murray - a neurologist and international leader mittee," she adds. "We have nursing, physio[therapy] and [occupational therapy] represented on our board. So we are trying to expand and broaden [our] scope."

The nomination process for next year's laureates ends on June 30, 2014. — Gordon Giddings, CMAJ

CMAJ 2014. DOI:10.1503/cmaj.109-4787 